\title{
A trainee's experience of group therapy with pre-adolescents
}

\author{
Elizabeth Procter
}

\begin{abstract}
Very fow trainees hove experience in group psychotherapy. I describe my expertence of co-facilitating a group for pre-adolescents who were being bullied. This proved a valuable leaming experience as part of a mulitidisciplinary team, and increased my understanding of how groups function and the particular problems involved in running a group for children.
\end{abstract}

The Royal College guidelines for trainees recommend a limited experience in both individual and group psychotherapy, under supervision. The recent article by Arnott et al (1993) highlights the fact that in their survey only $9 \%$ of trainees had experience of group therapy.

While working as a registrar in a child and adolescent out-patient unit I was able to work as a co-facilitator in a therapeutic group for pre-adolescents who were being bullied, run by a member of the multidisciplinary team, an occupational therapist. This proved a valuable learning experience for me, both in my understanding of how groups function and in the particular problems involved in running a group for children.

\section{Background to the group}

The two consultants were aware of several children coming to the unit who had been referred with a variety of conduct and emotional disorders, all experiencing difficulties with their peer group and complaining of being bullied. It was decided to run a closed group for six weeks, three sessions centering on bullding self-esteem and confidence, and three sessions on assertiveness. Nine children were suggested for the group and seen individually by myself or AS, the occupational therapist. Seven children decided to join the group with an age range of seven years nine months to 13 years. Five were boys and two were girls. The group ran for six weeks with sessions lasing 90 minutes. There was an opportunity for parents to meet informally when the group was running, as a room and coffee making facilities had been made available for them.

\section{Running the group}

The format of the group included introductory games, a period of work on a particular topic followed by a break for juice and biscuits, games to reinforce the week's theme and a plece of work to do between the sessions. Each session ended with the 'compliments' game whereby everyone sat in a circle and in turn paid a compliment to the person on their right.

Over the six sessions a variety of issues were raised: rules and rule breaking, bullying and being bullied, 'mouse-like' and 'monster-like' behaviour, recognising and expressing feelings and how to deal with angry feelings, and valuing oneself. In the course of the six weeks we used art work, role play, video recording and games as well as encouraging discussion.

Attendance was good, only one child missed one session because of ill health. The outcome of the group was felt to be positive for five of the children. When asked what had been the best thing about coming to the group one girl said it had been making friends with her bully. Another child said that he had stopped being bullied. For two children coming to the group had exacerbated their difficulties. A was the youngest member of the group and over the weeks he became increasingly disruptive. We felt that the age differences were too marked for him and that he needed a more comparable peer group or some individual therapy. B had very low self esteem and became frustrated with his inability to change and often expressed his anger in the group. He did make one special friend in the group, but we felt that he would benefit from some individual sessions to explore his feelings.

\section{Comments}

I found participating in the planning and running of the group an invaluable learning experience. Each session required an hour of joint preparation, and after the session time was spent debriefing and writing up notes. I was able to experience the different stages of growth of the group, the setting up of ground rules, fighting and conflict between group members, the sense of cohesion and belonging to the group, the productive working together and issues around the group ending. I was able to recognise some of the therapeutic factors at work in the group, such as 
universality, altruism, instillation of hope, and interpersonal learning. When I reflect now on the group I have a kaleidoscope of impressions, from the invigorating freshness and the direct communications of the children, their constant movement and short attention span, the noise level and exuberance, and precious quiet moments when a child would share some inner truth with the group, as well as my own feelings of exhaustion, joy or despair. There was value in seeing how a child's behaviour differed in the group from his or her behaviour in family or individual sessions.

As group facilitators we encountered three sources of tension.

(a) Discipline within the group. Were we therapists or teachers? This was highlighted by the children's sense of justice and their demand that we deal with people who broke the group rules.

(b) Should we use a creative or a structured approach?

(c) How should we accommodate the noisy assertive behaviour of some group members and encourage the quiet shy members to feel valued?

The most useful strategy was to ignore negative behaviour and re-inforce positive behaviour, and to recognise the limited concentration span of some children, thereby having brief work sessions interspersed with play.

\section{Acknowledgements}

I am grateful to Anita Sabey, occupational therapist, for her advice and support, and to Dr $M$. Ellis and Dr L. Hewson for their encouragement.

\section{Reference}

ARnott, S., Wilkinson, E. \& Arlard, P. (1993) A survey of psychotherapy experience among psychiatric registrars. Psychiatric Bulletin, 17, 721-723.

Elizabeth Procter, Registrar in Psychiatry, Stonehouse Hospital, Dartford DA2 6AU 
BJPsych
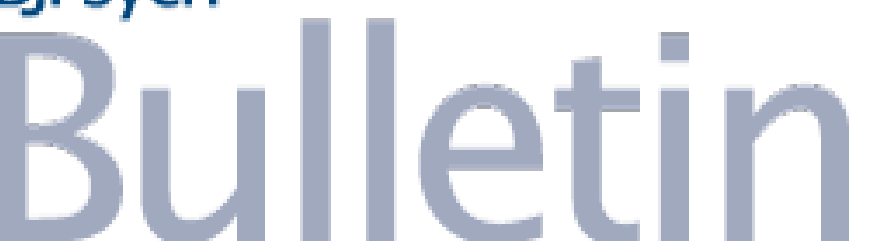

A trainee's experience of group therapy with pre-adolescents

Psychiatric Bulletin 1994, 18:485-486.

Access the most recent version at DOI: $10.1192 / \mathrm{pb} .18 .8 .485$

References This article cites 0 articles, 0 of which you can access for free at: http://pb.rcpsych.org/content/18/8/485\#BIBL

Reprints/ To obtain reprints or permission to reproduce material from this paper, please write permissions to permissions@rcpsych.ac.uk

You can respond /letters/submit/pbrcpsych;18/8/485

to this article at

Downloaded http://pb.rcpsych.org/ on September 26, 2017

from Published by The Royal College of Psychiatrists

To subscribe to BJPsych Bulletin go to: http://pb.rcpsych.org/site/subscriptions/ 